\title{
Environmental degradation in the transnational area of Changbai Mountain based on multiple remote sensing data
}

\author{
Yaohang Sun ${ }^{1}$, Ying $\operatorname{Nan}^{1}$, Da Zhang ${ }^{1}$, Xuegang Gan ${ }^{1}$, and Lichen Piao ${ }^{1}$ \\ ${ }^{1}$ Yanbian University
}

September 25, 2021

\begin{abstract}
Rapidly and effectively assessing environmental degradation is essential for promoting regional sustainable development in the transnational area of Changbai Mountain (TACM). However, comprehensively understanding environmental degradation in the TACM is still inadequate. In this study, we developed an environmental degradation index (EDI) by using multiple remote sensing data, including enhanced vegetation index (EVI), gross primary productivity (GPP), land surface temperature (LST), and MODIS surface reflectance products. We then evaluated its performance comparing with the remote sensing ecological index (RSEI), and assessed the environmental degradation across the whole TACM, in the subregions of China, the Democratic People's Republic of Korea (DPRK), and Russia during 2000-2019. The results indicated that the EDI had the advantages of simplicity and rapidity, which can assess the environmental degradation in the TACM across long-time scales and large spatial extent. The TACM experienced a downward trend of environmental changes from 2000 to 2019. Degraded environment areas $(49,329.50 \mathrm{~km} 2)$ accounted for $30.09 \%$ of the entire TACM. The largest area of the degraded environment was on the DPRK's side (i.e., 25,395.00 km2), which was 5.6 times larger than that on the Russian side and 1.3 times larger than that on the Chinese side. Hotspot areas that experienced significant environmental degradation just covered $17.69 \%$ of the land area of the TACM, the area of environmental degradation in them accounted for $33.89 \%$ of the total degraded environment across the whole TACM. We suggest that international cooperation policies and measures ought to be enacted to promote regional sustainable development.
\end{abstract}

\section{Hosted file}

20210902-Manuscript.docx available at https://authorea.com/users/436869/articles/538901environmental-degradation-in-the-transnational-area-of-changbai-mountain-based-onmultiple-remote-sensing-data 